\title{
THE EFFECT OF ZSM-5 CATALYST SUPPORT IN CATALYTIC PYROLYSIS OF BIOMASS AND COMPOUNDS ABUNDANT IN PYROLYSIS BIO-OILS
}

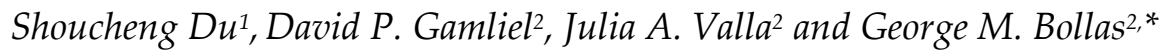

${ }^{1}$ Department of Materials Science E Engineering, University of Connecticut, Storrs, 97 North Eagleville Road, Storrs, CT 06269-3136, USA.

2Department of Chemical \& Biomolecular Engineering, University of Connecticut, Storrs, 191 Auditorium Road, Unit 3222, Storrs, CT 06269, USA.

*Corresponding Author: Tel: +1-860-486-4602. Email: george.bollas@uconn.edu;

\begin{abstract}
Supported ZSM-5 is commonly used for in-situ biomass pyrolysis vapor upgrading in fluidized bed reactors. In this work, we investigate the effects of catalyst support on the pyrolysis product distribution by studying pyrolysis of woody biomass and bio-oil derived model compounds. Specifically, miscanthus, toluene and furan are catalytically pyrolyzed over bulk ZSM-5, supported ZSM-5 and a commercial $\mathrm{Al}_{2} \mathrm{O}_{3}$ support. The pyrolysis product distributions of biomass and each model compound are presented and discussed. The coke formed on the catalysts and support, which is also responsible for catalyst deactivation, is analyzed using temperature programmed oxidation (TPO). It is shown that pyrolysis of miscanthus, toluene and furan over supported ZSM-5 produces less liquid products, particularly mono-aromatic hydrocarbons, than over bulk ZSM-5, mainly due to the dilution of Brønsted acid sites by the catalyst support. The Lewis acidity of the $\mathrm{Al}_{2} \mathrm{O}_{3}$ support promotes alkylation and cyclization of propylene leading to enhanced benzene production. The Lewis acidity of the support also enhances coke production with a less condensed structure, while selectivity to poly-aromatics is deteriorated.
\end{abstract}

KEYWORDS: • Catalyst support・ Alumina $\bullet$ ZSM-5 $\bullet$ Biomass pyrolysis $\bullet$ Model compounds 


\section{INTRODUCTION}

Biomass conversion to fuels and platform chemicals has received considerable attention due to its capability to minimize $\mathrm{CO}_{2}$ emissions and its sustainability [1-6]. Fast pyrolysis is a promising strategy for bio-oil production from a variety of biomass feedstocks. Catalytic fast pyrolysis (CFP) is the pyrolysis of biomass at high heating rate in the presence of catalyst, which enhances the selectivity to deoxygenated compounds in the bio-oil. So far, ZSM-5 has been shown to be the best catalyst for improving the bio-oil quality in biomass pyrolysis, mainly due to its shape selective pore structure [7-9]. Fluidized bed reactors have been extensively studied in biomass pyrolysis due to their scalability, excellent mass and heat transfer properties, good mixing between the solids and suspending fluid, uniform catalyst distribution and so forth [1012]. Catalyst supports have been used and incorporated with zeolites (e.g., Y and ZSM-5 zeolite) to assist fluidization, heat transfer from the regenerator to the reactor, and protect the zeolite from poisoning and attrition [13-16]. Moreover, in the fluid catalytic cracking (FCC) process, the increased catalyst acidity by the extra-framework structure and the large pores of the support is responsible for the cracking of large feed molecules to smaller-size molecules, enabling their diffusion into the zeolite channels for additional catalytic upgrading reactions $[13,17,18]$.

The effect of the support on product distribution in biomass catalytic pyrolysis is not as widely studied as for FCC. In particular, limited effort has been put into understanding the impact of Brønsted and Lewis acid site density and extra-framework structure of the support on the product distribution from biomass catalytic pyrolysis. Iliopoulou et al. [19] found that pyrolysis over alumina-silica supported ZSM-5 produced more organic compounds, and lower coke and gas yields than that over bulk ZSM-5, due to the dilution of the acid site density by the matrix of the supported ZSM-5. Catalytic upgrading of pyrolysis vapors over alumina-silica and alumina supports, and supported ZSM-5 was studied by Stefanidis et al. [7]. Compared to supported ZSM-5, the supports enhanced the production of the solids, while reducing the yields to the total liquid and organic phase products. Previously, we have catalytically pyrolyzed miscanthus in a spouted bed reactor over supported ZSM-5 and alumina matrix, to investigate the effect of active sites in the matrix on product distribution [10]. It was shown that pyrolysis over alumina 
matrix produced more solid product than that over supported ZSM-5 catalyst. Moreover, the alumina matrix did not improve the quality of the bio-oil, or enhance the selectivity to desired monocyclic aromatic hydrocarbons (MAHs).

The objective of this work is to understand the effect of the catalyst support on the product distribution from biomass catalytic pyrolysis and bio-oil upgrading. Specifically, we focus on understanding the contribution of Lewis acidity of the support to the biomass pyrolysis product distribution. Furthermore, by pyrolyzing bio-oil derived model compounds, the impact of the catalyst support on the polymerization and deoxygenation reactions of important pyrolysis oil intermediates are studied. Large biomass-derived molecules can potentially undergo decomposition and polymerization reactions on the catalyst support. In this work, we focus on distinguishing the effects of bulk ZSM-5 catalyst and catalyst support on the secondary reactions (bio-oil upgrading) of biomass catalytic pyrolysis [3,20]. In this context, molecules with kinetic diameters smaller than the largest ZSM-5 cavity (7 $\mathrm{A}$ ) [21] were chosen as probe molecules. Considering the typical composition of the bio-oil produced from fast pyrolysis of biomass [22,23], we used toluene and furan as compounds representative of the bio-oil aromatic hydrocarbons and aromatic oxygenates, respectively.

\section{EXPERIMENTAL SECTION}

\subsection{Feedstock and catalysts}

In this work, miscanthus was chosen as the biomass feedstock. The biomass feed was grinded and sieved to $80-175 \mu \mathrm{m}$ particle size. Proximate and ultimate analyses of miscanthus were shown in a previous study [10]. Toluene $(99.8 \%)$ and furan ( $\geq 99 \%)$ were purchased from Sigma Aldrich and used in catalytic pyrolysis experiments.

Bulk ZSM-5 zeolite (CBV 8014) from Zeolyst International, Inc., and commercial spray dried supported ZSM-5 catalyst (ZSM-5 and support fractions are proprietary) and bare alumina from W. R. Grace \& Co, were used in the experiments. All the catalysts were calcined in air at $550{ }^{\circ} \mathrm{C}$ for 5 hours prior to experiments. Nitrogen adsorption/desorption isotherms and pore size distribution of the two ZSM-5 catalysts and alumina support are shown in Figure $\mathbf{1}(\mathbf{a}, \mathbf{b})$. As expected, the bulk ZSM-5 is very microporous. In contrast, supported ZSM-5 and the alumina 
support contain a small fraction of micropores, and a large fraction of meso- and macropores. FEI Quanta FEG 250 Scanning Electron Microscopy (SEM) and FEI Strata 400 STEM Dual Beam System Focused Ion Beam (FIB)/Energy Dispersive X-ray spectroscopy (EDX) images of the supported ZSM-5 are shown in Figure 1 (c) and (d), respectively. The analysis conditions and procedures for conducting SEM and FIB/EDX has been reported previously [24]. The FIB/EDX images show the silica-alumina distribution of the ZSM-5 support used in this study.
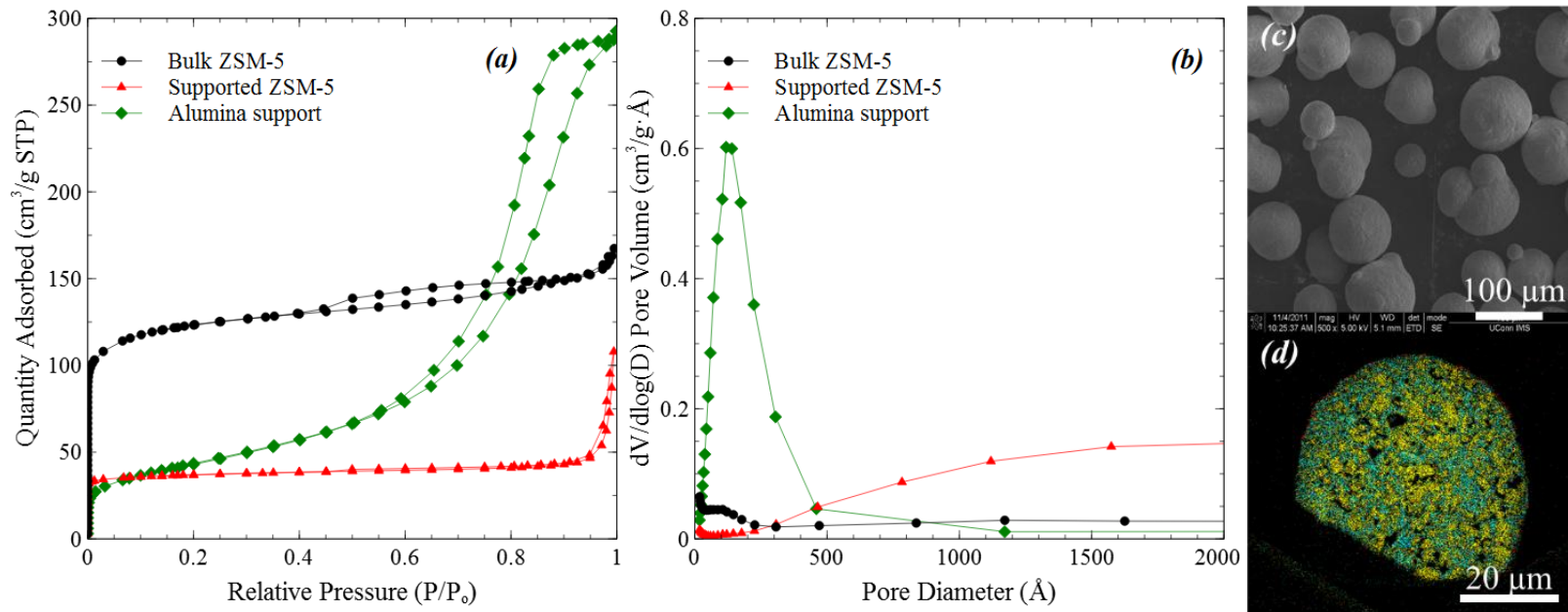

Figure 1. (a) Nitrogen adsorption/desorption isotherms and (b) pore size distribution of bulk ZSM-5, supported ZSM-5 and alumina support, calculated from adsorption isotherms with the BJH method; (c) SEM and (d) FIB/EDX images of supported ZSM-5 (Yellow color represents Si; cyan color Al).

Another key property of pyrolysis catalyst is in the acid site density. Acidity analysis was performed by NICOLET 6700 Diffuse Reflectance Infrared Fourier Transform Spectroscopy (DRIFTS) from Thermo Scientific. The catalysts were first calcined in nitrogen at $500{ }^{\circ} \mathrm{C}$ for $1 \mathrm{~h}$. Samples were cooled to $130{ }^{\circ} \mathrm{C}$, then dosed with pyridine (99 wt\%) up to saturation. Physisorbed pyridine was removed isothermally at $230^{\circ} \mathrm{C}$ for $1 \mathrm{~h}$. Final spectra were taken after cooling to $130^{\circ} \mathrm{C}$, using the unexposed sample as the background. Extinction coefficients of 1.67 $\mathrm{cm} / \mu \mathrm{mol}$ and $2.22 \mathrm{~cm} / \mu \mathrm{mol}$ were used for calculation of Brønsted and Lewis acid site concentrations, respectively [25]. Pyridine sorption revealed Brønsted and Lewis acid site densities, with different site distributions for the bulk ZSM-5, supported ZSM-5 and alumina 
support (Table 1). As shown in Table 1, the bulk ZSM-5 catalyst is very rich in Brønsted acid sites, whereas alumina support contains only Lewis acid sites.

Table 1. Physicochemical characterization of the bulk ZSM-5, supported ZSM-5 and alumina support used in this work. ${ }^{a}$

\begin{tabular}{llllllll}
\hline & \multicolumn{2}{c}{ Physical property } & \multicolumn{3}{c}{ Porosity $^{b}$} & \multicolumn{3}{l}{ Acid site density } \\
\cline { 2 - 7 } & Qbulk & $\mathrm{d}_{\mathrm{p}}$ & $\mathrm{S}_{\text {total }}$ & $\mathrm{d}_{\text {pore }}$ & B.s. & L.s. & B.s./L.s. \\
\hline Bulk ZSM-5 & 500 & $0.5 \sim 2$ & 419 & 64 & 201 & 65 & 3.09 \\
Supported ZSM-5 & 800 & $75 \sim 175$ & 124 & 363 & 36 & 9 & 4.34 \\
$\mathrm{Al}_{2} \mathrm{O}_{3}$ & 860 & $70 \sim 230$ & 158 & 97 & - & 78 & Lewis \\
\hline
\end{tabular}

${ }^{a}$ Qbulk stands for bulk density $\left(\mathrm{kg} / \mathrm{m}^{3}\right) ; \mathrm{d}_{\mathrm{p}}$, particle size $(\mu \mathrm{m})$; Stotal, BET surface area $\left(\mathrm{m}^{2} / \mathrm{g}\right)$; $\mathrm{d}_{\text {pore, }}$ pore size $(\AA)$, BJH adsorption average pore width (4V/A); B.s., Brønsted acid site density ( $\mu \mathrm{mol} / \mathrm{g})$; L.s., Lewis acid site density ( $\mu \mathrm{mol} / \mathrm{g})$.

${ }^{b}$ Porosity analysis was performed in Micromeritics ASAP 2020 Accelerated Surface Area and Porosimetry System. Samples were degassed at $250{ }^{\circ} \mathrm{C}$ under vacuum for $12 \mathrm{~h}$ before analysis.

\subsection{Catalytic pyrolysis of biomass}

Pyrolysis experiments were performed using a pyrolysis gas chromatography (PyGC, CDS Analytical 5200HP) microsystem, according to experimental protocols presented in Gamliel et al. [26]. Biomass and catalyst were physically mixed together in a catalyst to biomass $(\mathrm{C} / \mathrm{B})$ ratio of 5:1. Exactly $5 \mathrm{mg}$ of catalyst/biomass mixture was loaded into a quartz tube microreactor (1.9 mm I.D., $25 \mathrm{~mm}$ length) between two slugs of quartz wool, and then the microreactor was placed in a resistively heated coil probe. Ar was used as the carrier gas, at constant $50 \mathrm{sccm}$ flowrate for the duration of the experiment. The pyrolysis temperature and heating rate were $600{ }^{\circ} \mathrm{C}$ and $999^{\circ} \mathrm{C} / \mathrm{s}$, respectively. The set-point temperature was held for $20 \mathrm{~s}$, and all lines were maintained at $300{ }^{\circ} \mathrm{C}$ to prevent condensation of pyrolysis vapors.

Liquid products were transferred from a cold Tenax trap to a gas chromatograph equipped with a mass spectrometer (GC-MS, Agilent 6890 GC with 5973N MS) via a heated line. Quantification was accomplished using external standards, for which the semi-quantification method was applied. Permanent gas products passed through the trap to an online MS (Agilent 5975C) fitted with a gas sampling attachment (Diablo Analytical). The solid yield was 
determined via in-situ oxidation of all remaining residue in the microreactor, while monitoring the $\mathrm{CO}$ and $\mathrm{CO}_{2}$ signals on the MS. For consistency, all pyrolysis yields reported in this work are in terms of wt.\% of initial biomass. Carbon yield was also determined to be greater than 90 $\mathrm{mol} \% \mathrm{C}$, and all experiments were performed in triplicate to ensure precision.

\subsection{Catalytic pyrolysis of model compounds}

Catalytic pyrolysis of model compounds was performed in a specially designed fixed bed reactor (Figure 2). During the experiments, 3 gr of alumina or bulk and supported ZSM-5 were held in place by two plugs of quartz wool in a 1-inch diameter quartz tube reactor. The reactor was heated to $600{ }^{\circ} \mathrm{C}$ under Ar flow of $50 \mathrm{sccm}$. $1 \mathrm{gr}$ of reactant (toluene and furan) was then injected into the saturator, heated to $10{ }^{\circ} \mathrm{C}$ above the boiling point of the main reactant. Experiments with $0.17 \mathrm{gr}$ of propylene co-fed with toluene were also performed. The feed to catalyst ratio was kept at 3:1 for all the experiments with toluene and furan. The effects of catalyst to feed ratio on the production distribution of catalytic pyrolysis of toluene and furan were studied in a previous work [27]. The condensable products were collected in an impinger filled with $20 \mathrm{~mL}$ methanol in dry ice. A second impinger with additional $20 \mathrm{~mL}$ methanol was used in series to confirm complete condensation of any volatiles in the first impinger. An additional $15 \mathrm{~mL}$ of methanol was used to rinse the impinger and the base of the reactor tube to collect any condensates. The duration of each experiment was determined by the completion of reactions, detected as zero gas product in the reactor effluent. After cooling, the coked catalyst was removed from the reactor and separated from the quartz wool. Experiments with toluene and furan at each catalyst to feed ratio were performed at least three times to calculate the experimental standard deviation. The mass balance was evaluated and used as indication of the accuracy of the experiment. The experiments with toluene could achieved $\geq 90 \mathrm{wt} \%$ mass balance, whereas, in catalytic conversion of furan, $\geq 75 \mathrm{wt} \%$ mass balance was accepted due to the presence of unmeasured water in the liquid product.

Gas products were analyzed online with mass spectrometry (MS, Agilent 5975C, inert with triple axis detector). The MS was calibrated using standard gases $\left(\mathrm{H}_{2}, \mathrm{CH}_{4}, \mathrm{CO}, \mathrm{CO}_{2}, \mathrm{C}_{2} \mathrm{H}_{4}, \mathrm{C}_{3} \mathrm{H}_{6}\right.$, and Ar). Liquid products were analyzed using an Agilent 6890N Gas Chromatograph equipped 
with a 5973N mass selective detector (GC-MS) and Agilent DB-5 column. A split ratio of 50:1 and temperature program starting at isothermal setting at $40^{\circ} \mathrm{C}$, followed by a $10^{\circ} \mathrm{C} / \mathrm{min}$ ramp to $270{ }^{\circ} \mathrm{C}$ was applied for furan, benzene and toluene quantification. All other compounds were identified with a splitless injection and temperature program starting at $40{ }^{\circ} \mathrm{C}$, followed by a 1 ${ }^{\circ} \mathrm{C} / \mathrm{min}$ ramp to $87^{\circ} \mathrm{C}$ and a $20^{\circ} \mathrm{C} / \mathrm{min}$ ramp to $270{ }^{\circ} \mathrm{C}$. Quantification standards consisting of furan, benzene, toluene, xylene, styrene, indene, naphthalene were calibrated. All other compounds were analyzed using the semi-quantification method [28,29]. The weight percent of coke on catalyst and the coke yield were determined with temperature programmed oxidation (TPO) at temperatures up to $900{ }^{\circ} \mathrm{C}$ in a Q-500 thermogravimetric analyzer from TA instruments. In the TPO tests, samples were held at $120{ }^{\circ} \mathrm{C}$ for $30 \mathrm{~min}$ in order to remove moisture and then heated to $900{ }^{\circ} \mathrm{C}$ at a heating rate of $15 \mathrm{~K} / \mathrm{min}$ and constant air flow.

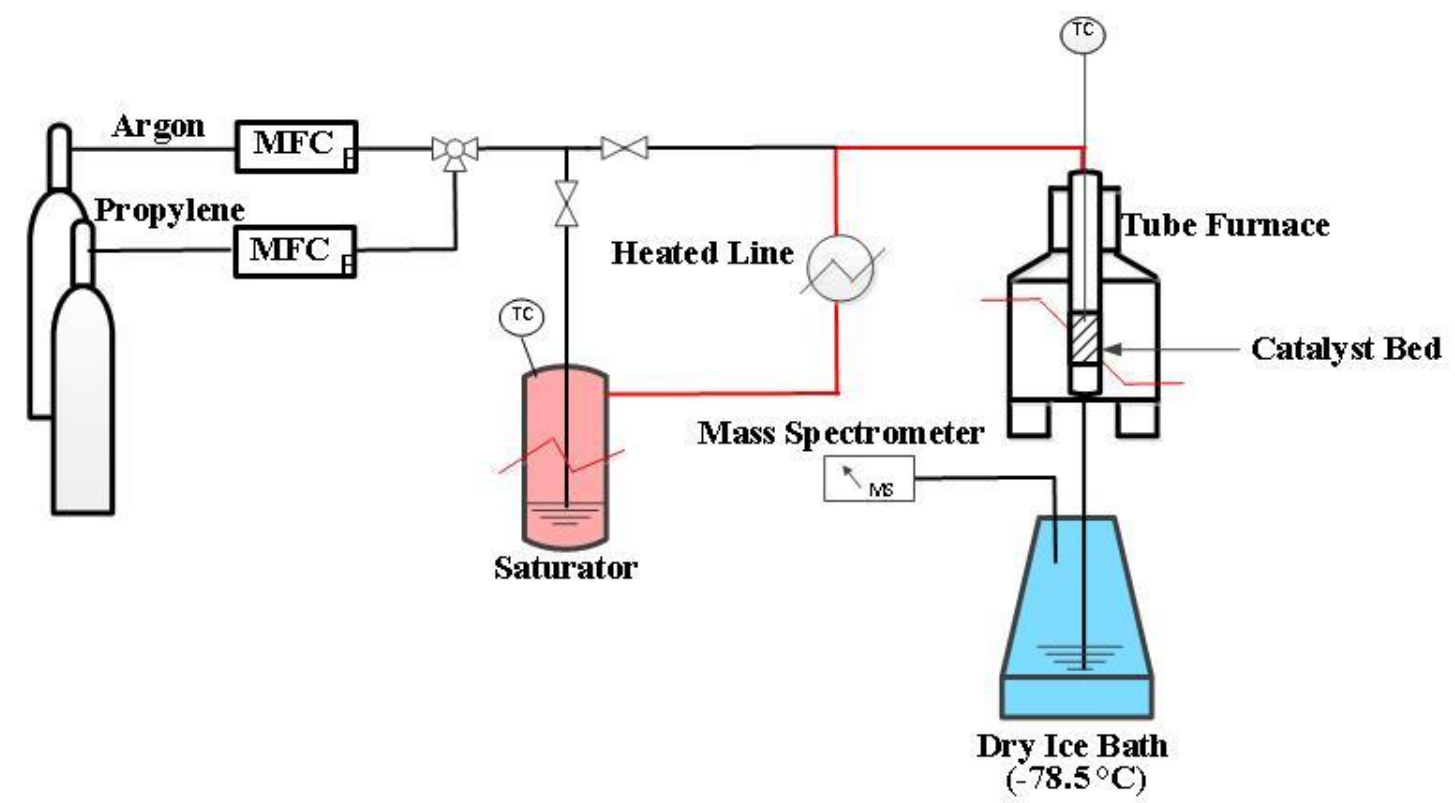

Figure 2. A schematic representation of the specially designed bench scale fixed bed reactor.

\section{RESULTS AND DISCUSSION}

\subsection{Effect of catalyst support on product distribution from biomass pyrolysis}

Figure 3 (a) shows the carbon yields to bio-oil, gas and solid (coke/char) from pyrolysis of miscanthus over bulk ZSM-5, supported ZSM-5 and alumina support. Pyrolysis with the two ZSM-5 catalysts resulted in higher liquid and gas yields compared to pyrolysis with the 
alumina support. Moreover, slightly higher solid yields were observed from pyrolysis over bare alumina, compared to the ZSM-5 catalysts. The enhanced solid formation may be attributed to the absence of Brønsted acidity, which is responsible for cracking the bulky coke and char precursors. Additionally, both the high concentration and strength of Lewis acid sites, as well as the large meso- and macro- pores in the alumina support may contribute to coke and char agglomeration $[7,30]$.

Pyrolysis of miscanthus over bulk ZSM-5 and supported ZSM-5 produced higher yields of hydrocarbons and phenols than that over alumina, whereas alumina failed to convert primary pyrolysis products, resulting in the presence of furans and other oxygenates, such as ketones and aldehydes in the bio-oil (Figure 3 (b)). Bulk ZSM-5 promoted the production of benzenes, indenes, and naphthalenes, whereas the supported ZSM-5 produced more phenols, furans, and other oxygenates. This is in agreement with Iliopoulou et al. [19], who found that, compared to the crystalline ZSM-5 zeolite, the supported ZSM-5 catalyst increased the production of phenols, possibly due to the mild Lewis acidic function of the silica-alumina matrix in combination with its mesoporous structure.
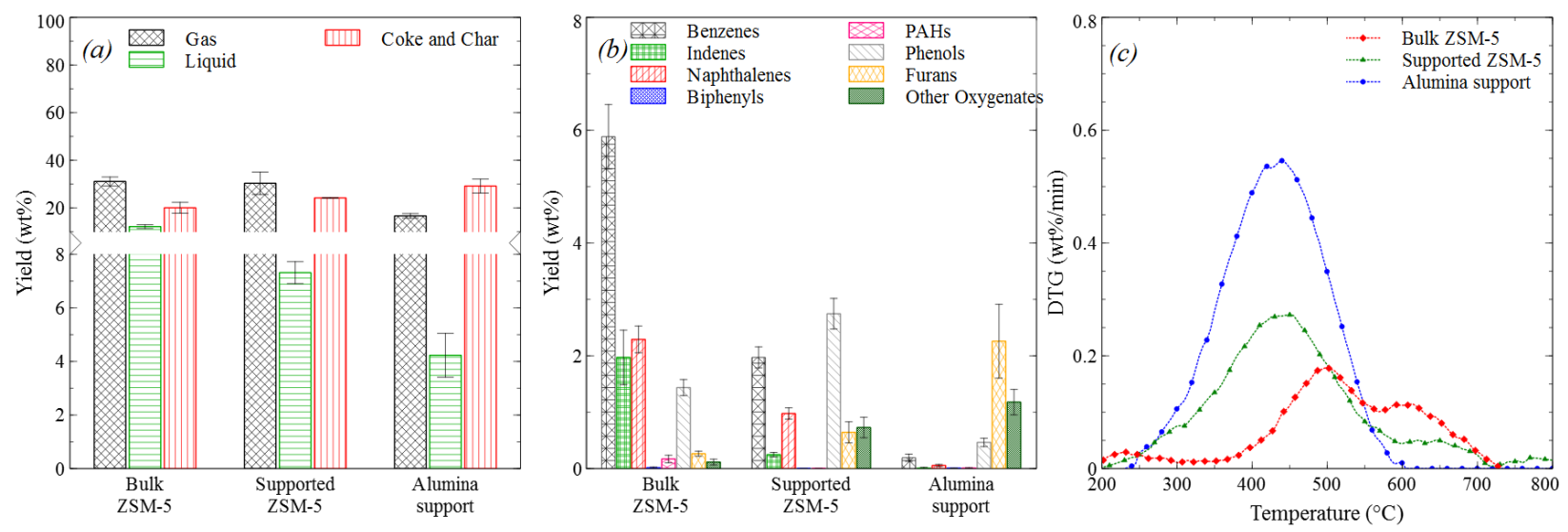

Figure 3. (a) Product distribution, (b) liquid product selectivity, and (c) TGA of the coke from catalytic pyrolysis of miscanthus over bulk ZSM-5, supported ZSM-5 and alumina support. Error bars represent the standard deviation of three replicated trials.

Catalyst deactivation is of great interest with regards to biomass catalytic pyrolysis and bio-oil upgrading, particularly when ZSM-5 catalyst is used [24,31,32]. In this study, we compared the TPO curves of the coked/charred bulk ZSM-5, supported ZSM-5 and alumina support after 
pyrolysis of miscanthus. As shown in Figure 3 (c), TPOs of coked/charred bulk ZSM-5 and supported ZSM-5 exhibited a low temperature peak and a high temperature peak, which represent char (higher oxygen content in the form of carbonyl groups produced from thermal decomposition of biomass) and coke (poly-aromatic hydrocarbons mainly deposited in the micropores of ZSM-5 produced from secondary polymerization of pyrolysis vapors), respectively [24]. Char produced from pyrolysis over bulk ZSM-5 had a more condensed structure (TPO peak shifted to higher temperature), compared with that over supported ZSM-5, possibly due to the considerable external Brønsted acidity of the bulk ZSM-5, as determined by collidine temperature programmed desorption (TPD) measurements [33]. Collidine is a large molecule, which is inaccessible to the ZSM-5 pores and binds selectively to external B.s. These external B.s. act on bulky char precursors, often cracking them and removing oxygen via decarbonylation and decarboxylation reactions. The lower oxygen content, in turn, results in a higher char oxidation temperature. Coking is largely a result of internal acidity, with oxidation temperatures after pyrolysis over bulk and supported ZSM-5 being similar, although there is noticeably more coke observed on the bulk ZSM-5. Correlations between TPO peak temperature and the condensation $(\mathrm{C} / \mathrm{H}$ ratio) of the char/coke can be found in Du et al. [24,27]. TPO of the coked/charred alumina support showed only one broad peak in the lower temperature region (about $440^{\circ} \mathrm{C}$ ), identified as char in the work of Du et al. [10]. The TPO analysis indicates that pyrolysis over alumina support produced more char than those over bulk ZSM-5 and supported ZSM-5. However, formation of poly-aromatic coke did not occur with alumina support in catalytic pyrolysis of miscanthus.

\subsection{Effect of catalyst support on product distribution in toluene pyrolysis}

\subsubsection{Product distribution in toluene pyrolysis}

Toluene was chosen as a biomass pyrolysis model compound, because it is often the most abundant MAH in the biomass pyrolysis hydrocarbon pool [34]. Figure 4 shows the product distribution from toluene pyrolysis over the three catalysts, performed in a fixed bed reactor at $600{ }^{\circ} \mathrm{C}$. As shown in Figure 4 (a), pyrolysis of toluene over bulk ZSM-5 resulted in better liquid selectivity, compared to pyrolysis with the supported ZSM-5 and alumina support, which is 
consistent with the results from pyrolysis of miscanthus, observed in the previous section. However, the coke yield was higher from pyrolysis over bulk ZSM-5 than that over supported ZSM-5. The highest coke yield was observed in pyrolysis over alumina. This suggests that coke formation is enhanced by Lewis acidity (Table 1). Low numbers of Lewis acid sites were also summarized by Custodis et al. [35], to be responsible for lower coke yields and improved catalyst activity.
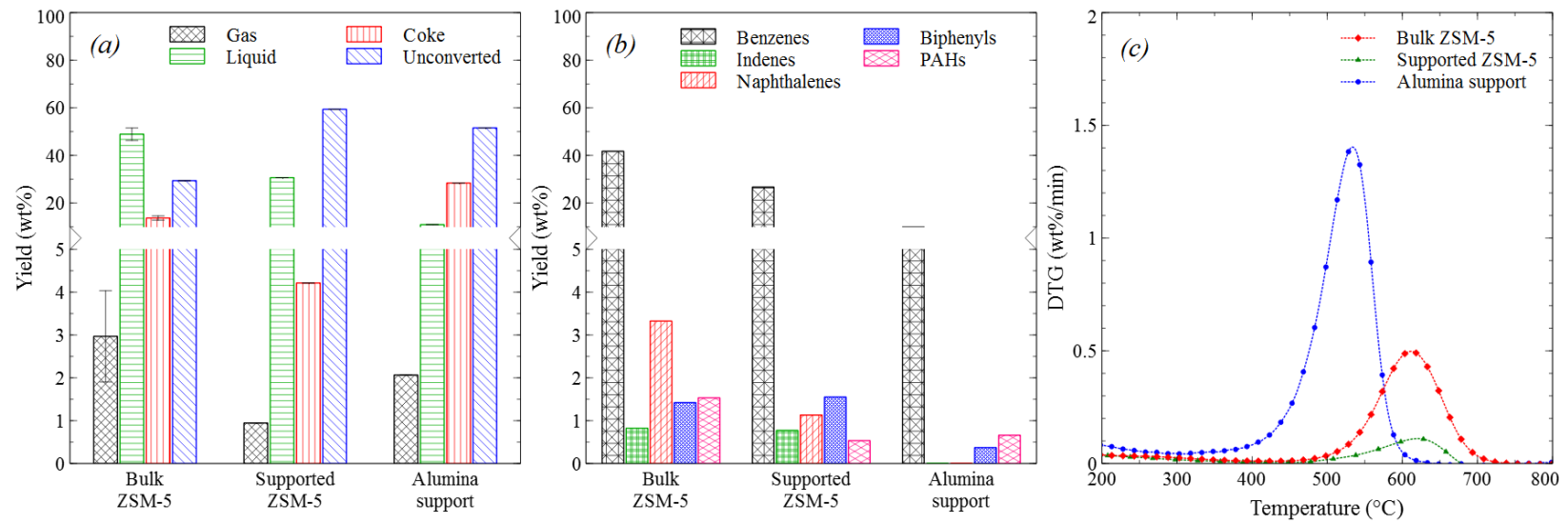

Figure 4. (a) Overall product distribution from toluene pyrolysis in a fixed bed reactor, (b) liquid product yields, and (c) TGA of the coke from catalytic conversion of toluene over bulk ZSM-5, supported ZSM-5 and alumina support. Note: "Unconverted" is considered as the mass of the feed compound detected after reaction over the mass of the total feed; the yield of "Liquid" the mass of the total liquid products (not including the feed compound) over the mass of the total feed.

Figure 4 (b) presents the liquid product distribution from catalytic pyrolysis of toluene. MAHs (e.g. benzene and its derivatives) were the most abundant compounds in the liquid products. Bulk ZSM-5 significantly increased conversion to benzenes, naphthalenes and PAHs, compared to the supported ZSM-5 and alumina support, which is mainly attributed to the abundance of Brønsted acid sites. Pyrolysis over bulk ZSM-5 and supported ZSM-5 resulted in a fair amount of indenes, naphthalenes and biphenyls, whereas they were seldom in the products from pyrolysis over the alumina support. This means that formation of indenes, naphthalenes and biphenyls is enhanced by the Brønsted acid sites of the catalyst. Overall, although some benzenes, biphenyls and PAHs are produced over the Lewis acid sites of the alumina support, none of the liquid products shown in Figure 4 (b) are promoted by Lewis acidity, compared with Brønsted acid sites. 
The TPOs of coked bulk ZSM-5, supported ZSM-5 and alumina support all present a single peak, representing polymeric coke (Figure 4 (c)). However, the peak temperature of the coke produced from pyrolysis over the two ZSM-5 catalysts is higher than that over the alumina support. This means that a coke with less condensed structure (higher H/C molar ratio) is formed over the Lewis acid sites of $\mathrm{Al}_{2} \mathrm{O}_{3}[24,27]$ and is less confined by the spatial limitations of the meso- and macro-pores of the alumina support (Figure 1).

\subsubsection{Competitive reaction of toluene and propylene}

Brønsted acid sites are well known olefin pyrolysis initiators, allowing the formation of a carbenium ion [36]. To test this hypothesis, we performed experiments to study the differences in the product distribution between the ZSM-5 catalysts, which is rich in Brønsted acidity, and the alumina support, which lacks Brønsted acid sites. Figure 5 shows the difference in yields between pyrolysis of toluene and toluene co-fed with propylene, corrected for the additional mass of reactant propylene, following the equation:

Yield difference $(\%)=\left(\begin{array}{c}\frac{\text { Mass of product from pyrolysis of toluene and propylene }}{\text { Mass of toluene and propylene feed }} \\ -\frac{\text { Mass of product from pyrolysis of toluene }}{\text { Mass of toluene feed }}\end{array}\right) \times 100$

As shown in Figure 5 (a), both ZSM-5 catalysts show much higher gas selectivity compared to the alumina support, but the liquid and solid yields do not show significant differences when propylene was co-fed for all catalysts. Moreover, competition between toluene and propylene for the Brønsted acid sites was evident in the experiment over the supported ZSM-5, as reflected by the lower toluene conversion when propylene was used. The enhanced gas production in the presence of supported ZSM-5 indicates that a relatively high amount of Brønsted active sites of supported ZSM-5 was occupied by propylene, instead of toluene, when they were co-fed (propylene pyrolysis produces higher gas yield than toluene pyrolysis [27]). This phenomenon is not as obvious with the bulk ZSM-5, possibly because of its abundance of Brønsted active sites, compared to supported ZSM-5. As for the liquid product distribution (Figure 5 (b)), it is interesting that co-feeding propylene negatively affects benzenes yield over both ZSM-5 catalysts, but over alumina the benzenes yield increased. This means that alkylation and 
cyclization of propylene, forming benzene, is more favorable on the Lewis acid sites than toluene cracking reactions.

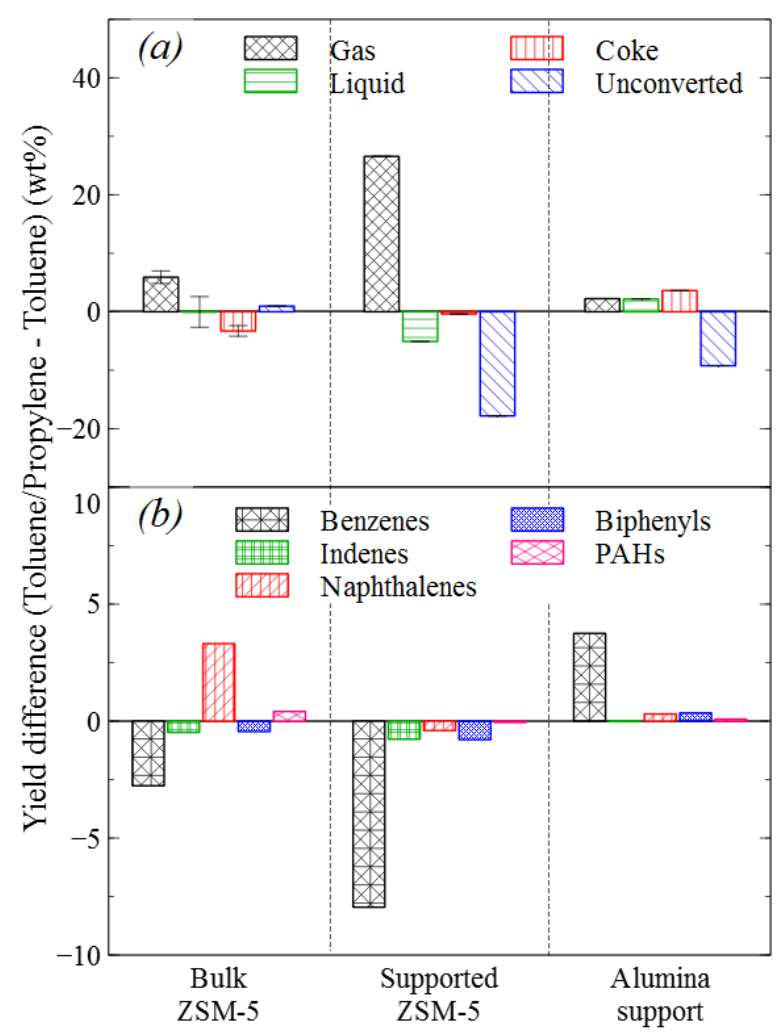

Figure 5. The difference between pyrolysis of toluene with propylene co-fed and pyrolysis of toluene in (a) product yield and (b) liquid distribution.

\subsection{Effect of catalyst support on product distribution in furan pyrolysis}

Furanic compounds are essential primary pyrolysis compounds, resulting from the thermal and catalytic decomposition of cellulose and hemi-cellulose [37]. Furan was pyrolyzed under the same conditions as toluene, and the product distribution from furan pyrolysis is presented in Figure 6. As shown in Figure 6 (a), pyrolysis of furan over bulk ZSM-5 and supported ZSM-5 results in higher conversion of the feed and higher liquid and gas yields than pyrolysis with alumina support. Consistent with the previous results, the highest coke yield was observed in pyrolysis over alumina, while higher coke yield was observed over bulk ZSM-5 compared to the supported catalyst. 

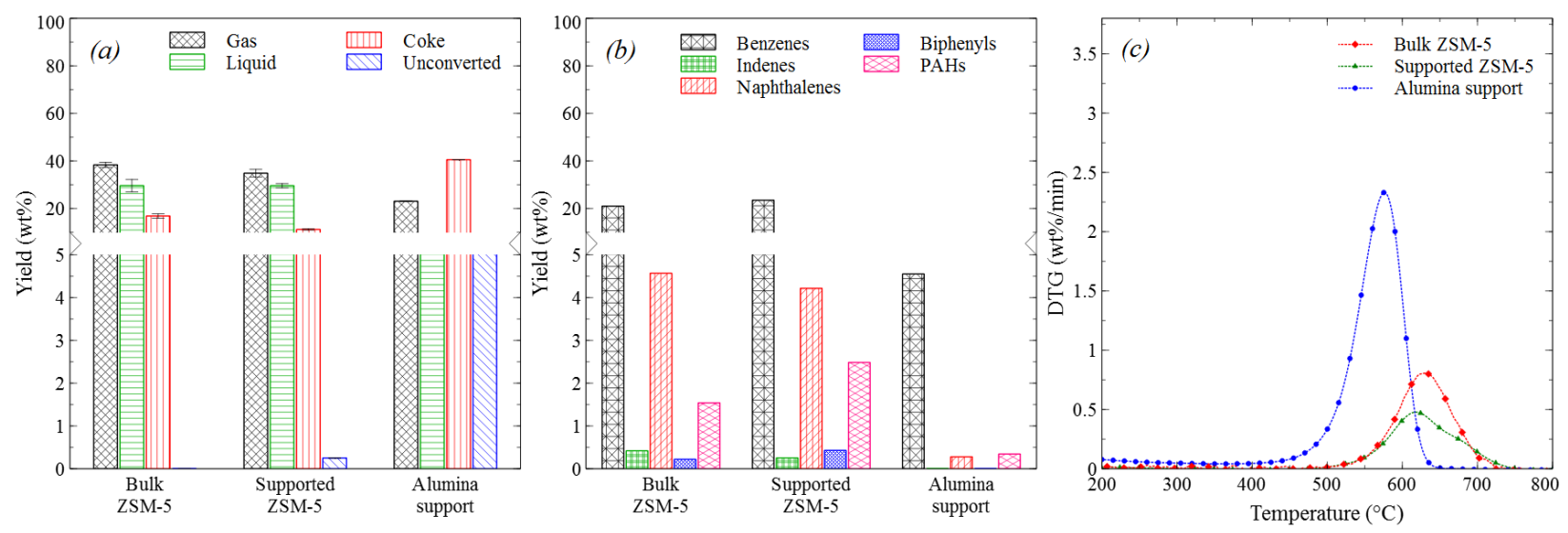

Figure 6. (a) Product distribution, (b) liquid product selectivity, and (c) TGA of the coke from catalytic conversion of furan over bulk ZSM-5, supported ZSM-5 and alumina support.

Figure 6 (b) presents the liquid product distribution from catalytic pyrolysis of furan. In pyrolysis with either ZSM-5 catalyst, a similar amount of naphthalenes and PAHs was obtained, whereas they were formed in much lower yields on the alumina support. Interestingly, supported ZSM-5 produces higher yields of PAHs than the bulk ZSM-5 during the pyrolysis of furan, as opposed to the results from pyrolysis of toluene. This might be due to the increased rate of deactivation of the bulk ZSM-5 catalyst due to water/steam produced during furan pyrolysis [38]. This effectively reduces the number of Brønsted acid sites of the bulk ZSM-5, which may also explain the smaller difference in coke yield between the bulk ZSM5 and supported ZSM-5 during furan pyrolysis, compared to that from toluene pyrolysis. As shown in Figure 6 (c), the peak temperature of the coke produced from pyrolysis over two ZSM-5 catalysts was consistently higher compared to the pyrolysis over the alumina support. This trend is consistent with what was shown in the TPO of toluene pyrolysis coke. 


\section{CONCLUSIONS}

In this study we have investigated the effects of catalyst support on pyrolysis product distributions of reactants relevant to biomass pyrolysis. Miscanthus, toluene and furan were catalytically pyrolyzed over bulk ZSM-5, supported ZSM-5 and alumina support. The product distributions and the characteristics of coke (and char) from pyrolysis of biomass and each model compound over ZSM-5 catalysts and catalyst support were compared and discussed. The following main conclusions were drawn:

- Pyrolysis of miscanthus, toluene and furan over supported ZSM-5 produces less liquid products, particularly small aromatic hydrocarbons, than that over bulk ZSM-5, mainly due to the dilution of Brønsted acid site density caused by the catalyst support.

- In pyrolysis of miscanthus, toluene and furan, the Lewis acidity of the support does not promote the production of the aromatic products, but contributes to enhanced coke formation.

- Alkylation and cyclization of propylene, leading to benzene formation, is more favorable than toluene cracking on Lewis acid sites.

- Coke formed from pyrolysis over alumina support shows a less condensed structure, compared with that from pyrolysis over ZSM-5 catalysts.

In summary, the support of a biomass catalytic pyrolysis catalyst needs to be carefully designed, taking into consideration the impacts of diluting Brønsted acidity and increasing Lewis acidity. Catalyst support formulations that are well established in oil refining are not ideal for biomass catalytic pyrolysis.

\section{ACKNOWLEDGMENTS}

This work was supported by the National Science Foundation under Grant No. CBET 1236738. The authors would like to thank W.R. Grace \& Co. for supplying the ZSM-5 catalyst and support used in this work. 


\section{REFERENCES}

[1] I. Noshadi, B. Kanjilal, S. Du, G.M. Bollas, S.L. Suib, A. Provatas, F. Liu, R.S. Parnas, Appl. Energy 129 (2014) 112-122.

[2] A. Fischer, S. Du, J.A. Valla, G.M. Bollas, RSC Adv. 5 (2015) 29252-29261.

[3] G.W. Huber, A. Corma, Angew. Chem. Int. Ed. Engl. 46 (2007) 7184-201.

[4] P.J. Dauenhauer, G.W. Huber, Green Chem. 16 (2014) 382.

[5] P. Brachi, R. Chirone, F. Miccio, M. Miccio, A. Picarelli, G. Ruoppolo, Fuel 128 (2014) 88-98.

[6] J.J. Bozell, L. Moens, D.C. Elliott, Y. Wang, G.G. Neuenscwander, S.W. Fitzpatrick, R.J. Bilski, J.L. Jarnefeld, Resour. Conserv. Recycl. 28 (2000) 227-239.

[7] S.D. Stefanidis, K.G. Kalogiannis, E.F. Iliopoulou, A.A. Lappas, P.A. Pilavachi, Bioresour. Technol. 102 (2011) 8261-7.

[8] A. Aho, N. Kumar, K. Eränen, T. Salmi, M. Hupa, D.Y. Murzin, Fuel 87 (2008) 2493-2501.

[9] S. Du, J.A. Valla, R.S. Parnas, G.M. Bollas, ACS Sustain. Chem. Eng. (2016) acssuschemeng.6b00450.

[10] S. Du, Y. Sun, D.P. Gamliel, J.A. Valla, G.M. Bollas, Bioresour. Technol. 169 (2014) 188-197.

[11] H. Zhang, R. Xiao, H. Huang, G. Xiao, Bioresour. Technol. 100 (2009) 1428-34.

[12] A. Aho, A. Tokarev, P. Backman, N. Kumar, K. Eränen, M. Hupa, B. Holmbom, T. Salmi, D.Y. Murzin, Top. Catal. 54 (2011) 941-948.

[13] R.J.F. C. H. Bartholomew, Fundamentals of Industrial Catalytic Processes, John Wiley \& Sons, 2011.

[14] M. Falco, E. Morgado, N. Amadeo, U. Sedran, Appl. Catal. A Gen. 315 (2006) 2934.

[15] G.M. Bollas, I.A. Vasalos, A.A. Lappas, D.K. Iatridis, S.S. Voutetakis, S.A. Papadopoulou, Chem. Eng. Sci. 62 (2007) 1887-1904.

[16] Z. Abu El-Rub, E. Bramer, G. Brem, Ind. Eng. Chem. Res. 45 (2004) 75-80.

[17] F. Ding, S.H. Ng, C. Xu, S. Yui, Fuel Process. Technol. 88 (2007) 833-845.

[18] D. Wallenstein, K. Schäfer, R.H. Harding, Appl. Catal. A Gen. 502 (2015) 27-41.

[19] E.F. Iliopoulou, S.D. Stefanidis, K.G. Kalogiannis, A. Delimitis, A.A. Lappas, K.S. 
Triantafyllidis, Appl. Catal. B Environ. 127 (2012) 281-290.

[20] T.R. Carlson, J. Jae, Y.-C. Lin, G.A. Tompsett, G.W. Huber, J. Catal. 270 (2010) 110124.

[21] E.L. First, C.E. Gounaris, J. Wei, C.A. Floudas, Phys. Chem. Chem. Phys. 13 (2011) 17339-58.

[22] J.H. Marsman, J. Wildschut, F. Mahfud, H.J. Heeres, J. Chromatogr. A 1150 (2007) $21-7$.

[23] M. Olazar, R. Aguado, J. Bilbao, A. Barona, AIChE J. 46 (2000) 1025-1033.

[24] S. Du, J.A. Valla, G.M. Bollas, Green Chem. 15 (2013) 3214.

[25] C.A. Emeis, J. Catal. 141 (1993) 347-354.

[26] D.P. Gamliel, S. Du, G.M. Bollas, J.A. Valla, Bioresour. Technol. (2015).

[27] S. Du, D.P. Gamliel, M. V. Giotto, J.A. Valla, G.M. Bollas, Appl. Catal. A Gen. 513 (2015) 67-81.

[28] R.N. Widyaningrum, T.L. Church, A.T. Harris, Catal. Commun. 35 (2013) 45-50.

[29] R.N. Hilten, K.C. Das, Fuel 89 (2010) 2741-2749.

[30] A. Galadima, O. Muraza, Energy Convers. Manag. 105 (2015) 338-354.

[31] H. Zhang, S. Shao, R. Xiao, D. Shen, J. Zeng, Energy \& Fuels (2014) 52-57.

[32] Á. Ibarra, A. Veloso, J. Bilbao, J.M. Arandes, P. Castaño, Appl. Catal. B Environ. 182 (2015) 336-346.

[33] D.P. Gamliel, H.J. Cho, W. Fan, J.A. Valla, Appl. Catal. A Gen. 522 (2016) 109-119.

[34] Y.-T. Cheng, G.W. Huber, ACS Catal. 1 (2011) 611-628.

[35] V.B.F. Custodis, S.A. Karakoulia, K.S. Triantafyllidis, J.A. vanBokhoven, ChemSusChem (2016) 1134-1145.

[36] R. Quintana-Solórzano, J.W. Thybaut, G.B. Marin, R. Lødeng, A. Holmen, Catal. Today 107-108 (2005) 619-629.

[37] K. Wang, K.H. Kim, R.C. Brown, Green Chem. (2013).

[38] E.G. Derouane, J.C. Védrine, R.R. Pinto, P.M. Borges, L. Costa, M.A.N.D.A. Lemos, F. Lemos, F.R. Ribeiro, Catal. Rev. 55 (2013) 454-515. 